\title{
Correction to: Diffusion coefficient analysis of aluminum electrolysis spent cathode as anode material for lithium-ion battery
}

\author{
Wenlong Huang ${ }^{1} \cdot$ Jiaxin Peng ${ }^{1} \cdot$ Jie Li $^{1} \cdot$ Xueyang Hou $^{1} \cdot$ Xingliang Zhang $^{1} \cdot$ Zhao Fang $^{1,2}$
}

Published online: 13 January 2022

๑) Springer-Verlag GmbH Germany, part of Springer Nature 2022

\section{Correction to: Ionics}

$$
\text { https://doi.org/10.1007/s11581-021-04398-y }
$$

Unfortunately, there are two typographical errors in the paper that we hereby would like to correct:

1 In all cases in which a temperature is not obviously meant, ${ }^{\circ} \mathrm{C}$ should be $\mathrm{C}$, which corresponds to the rate at which the battery is fully discharged in 1 hour. $\mathrm{x} \mathrm{C}$ means that the complete charge or discharge is achieved $\mathrm{x}$ times in 1 hour.

2 The unit of $\mathrm{F}$ (Faraday constant) should be $\mathrm{C} \mathrm{mol}^{-1}$.

Publisher's note Springer Nature remains neutral with regard to jurisdictional claims in published maps and institutional affiliations.

The original article can be found online at https://doi.org/10.1007/ s11581-021-04398-y.

Zhao Fang

fangzhao@xauat.edu.cn

1 School of Metallurgical Engineering, Xi' an University of Architecture and Technology, Xi' an 710055, Shaanxi, China

2 Shaanxi Province Metallurgical Engineering and Technology Research Centre, Xi'an 710055, China 